\title{
COVID-19 Pandemic: The Role of Traditional Medicine
}

\author{
Faisal Muhammad (iD) ${ }^{1, *}$ \\ ${ }^{1}$ Department of Public Health, Faculty of Allied Health Sciences, Daffodil International University, Dhaka, Bangladesh \\ "Corresponding author: B.Sc, MPH, MSS, Research Associate, Department of Public Health Daffodil International University (DIU), 102 \& 102/1 Shukrabad, Mirpur Road \\ Dhanmondi, Dhaka-1207, Bangladesh. Email: fokkanya@yahoo.com \\ Received 2020 July 02; Accepted 2020 July 21.
}

Keywords: COVID-19, Pandemic, Global Health, Traditional Medicine

\section{Dear Editor,}

As of June 01, 2020, more than six million confirmed cases of Coronavirus Disease 2019 (COVID-19) were reported globally. Currently, there is no medically approved treatment for COVID-19. However, efforts are underway to find the right treatment in almost all parts of the world, including traditional medicine in Africa and some parts of Asia and modern medicine in several European countries and the United States. In the search for potential treatments of COVID-19, the World Health Organization (WHO) welcomes innovations such as traditional medicine, repurposing drugs, and developing new therapies all over the world. Africa and some parts of Asia have a long history of using traditional medicine, and the WHO recognizes many benefits foe traditional medicines.

Traditional medicine has played a huge role in the treatment of several diseases. Currently, medicinal plants such as Artemisia annua are being considered as possible treatments for COVID-19, but they should be tested for efficacy and possible side effects. At present, the WHO is working with some research institutions around the world to select traditional medicine products with potential use for the treatment of COVID-19 after being investigated for clinical efficacy and safety. The WHO has been working with countries to ensure the safest and most effective use of traditional medicines, and it will continue to give support in exploring the benefits of traditional medicines in the prevention, control, and treatment of infections. Traditional medicines need to be robustly investigated to avoid putting the lives of people in danger during the period of this pandemic and beyond (1).

In China, scientists and doctors have recommended using Traditional Chinese Medicine (TCM) as a cure for COVID-19. During the Severe Acute Respiratory Syndrome (SARS) epidemic, TCM was effective in the treatment of infected people. The Chinese Government has ordered the use of TCM herbs to treat COVID-19 patients. It was reported that about $85 \%$ of COVID-19 patients in China received combined treatment with TCM and regular medication. Research shows that TCM herbs have antiviral ingredients. The potential contribution of TCM to health and well-being has been highlighted in the WHO global report on Traditional and Complementary Medicine (2-4). The TCM remedies for COVID-19 are even being sent to some countries such as Italy, Iran, etc. as international aids. However, scientists from other countries claim that it is dangerous to support therapies that have yet to be proven safe and effective (5).

A report released by the WHO stated that efforts are underway to find a treatment for COVID-19. However, caution must be taken against misinformation, especially on social media, about the effectiveness of certain remedies. A warning was released by the WHO regarding a COVID19 treatment called COVID Organics (CVO) announced by the Madagascar government that started to deliver the medicine to other African countries such as Equatorial Guinea, Guinea-Bissau, etc. A virtual meeting was held by the WHO with African traditional medicine experts few days after the announcement of CVO by Madagascar government, and the slammed of UN health agency by the Madagascar president for not endorsing CVO as a potential treatment of COVID-19. However, the WHO called for clinical trials of CVO and warned against the self-medication (6). In most of the areas with weak health systems and institutions, people are nervously hunting for ways to protect themselves from COVID-19. In some counties like Vietnam, Cambodia, Indonesia, Malaysia, Thailand, Philippines, etc., numerous remedies (such as drinking boiled lemongrass, drinking boiled garlic juice, swabbing nose with garlic juice, coconut oil, jamu drink, tong sui, kariyat, etc.) are circulating, more especially on the Internet, YouTube, and Facebook. In the current world, the internet is found to be

Copyright (C) 2020, International Journal of Infection. This is an open-access article distributed under the terms of the Creative Commons Attribution-NonCommercial 4.0 International License (http://creativecommons.org/licenses/by-nc/4.0/) which permits copy and redistribute the material just in noncommercial usages, provided the original work is properly cited. 
a source of misinformation (7). Many reports around the world claim the use of traditional medicine in the treatment of COVID-19. Several media reports claim that traditional medicines in combination with modern drugs are being used to treat COVID-19 patients in some parts of the world. Nevertheless, as of now, there is no concrete scientific evidence to support the use of traditional medicine in the treatment and management of COVID-19.

\section{Footnotes}

Conflict of Interests: The Author has no conflict of interest.

Funding/Support: None.

\section{References}

1. World Health Organization. WHO supports scientifically-proven traditional medicine. 2020, [cited May 28, 2020]]. Available from: https://www.afro.who.int/news/who-supports-scientificallyproven-traditional-medicine.
2. Ling CQ. Traditional Chinese medicine is a resource for drug discovery against 2019 novel coronavirus (SARS-CoV-2). J Integr Med. 2020;18(2):87-8. doi: 10.1016/j.joim.2020.02.004. [PubMed: 32122812]. [PubMed Central: PMC7129043].

3. Yang Y, Islam MS, Wang J, Li Y, Chen X. Traditional Chinese Medicine in the Treatment of Patients Infected with 2019-New Coronavirus (SARS-CoV-2): A Review and Perspective. Int J Biol Sci. 2020;16(10):170817. doi: 10.7150/ijbs.45538. [PubMed: 32226288]. [PubMed Central: PMC7098036].

4. Luo E, Zhang D, Luo H, Liu B, Zhao K, Zhao Y, et al. Treatment efficacy analysis of traditional Chinese medicine for novel coronavirus pneumonia (COVID-19): an empirical study from Wuhan, Hubei Province, China. Chin Med. 2020;15:34. doi: 10.1186/s13020-020-00317x. [PubMed: 32308732]. [PubMed Central: PMC7156896].

5. Cyranoski D. China is promoting coronavirus treatments based on unproven traditional medicines. Nature. 2020. doi: 10.1038/d41586020-01284-x.

6. Tih F. WHO holds meeting with African traditional medicine experts. 2020, [cited June 02, 2020]. Available from: https: //www.aa.com.tr/en/africa/who-holds-meeting-with-africantraditional-medicine-experts/1838004.

7. Nguyen D. Traditional Medicine and Quest for COVID-19 cure. 2020 Available from: https://yaleglobal.yale.edu/content/traditionalmedicine-and-quest-covid-19-cure. 